\title{
Financeirização global e Estados Nacionais ${ }^{1}$
}

Angelita Matos Souza?

Nossa exposição organizar-se-á em torno de três temas: 1. as transformações do capitalismo contemporâneo: a financeirização global; 2. o debate sobre o futuro dos Estados nacionais diante de tais transformações; 3. Imperialismo e Estados nacionais.

Por "financeirização global" devemos entender, conforme Braga ${ }^{3}$, o modo como se apresenta, atualmente, o "velho" capital financeiro. Este "modo de ser", hoje, do capital financeiro diz respeito às transformações recentes da economia mundial que, a partir dos EUA, foram se difundindo globalmente. Entre as principais transformações, o autor aponta: 1) a superioridade das taxas de crescimento da riqueza financeira em comparação às taxas de crescimento do produto e do estoque de capital; 2) a ampliação das funções financeiras no interior das corporações produtivas e a expressiva participação dos lucros financeiros nos lucros totais destas; 3) a transnacionalização, sem precedentes na história do capitalismo, das grandes empresas mundiais;

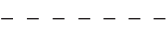

1 Nossa exposição utilizar-se-á, em larga medida, do texto de Bob Jessop, "A globalização e o Estado nacional”, Crítica Marxista, São Paulo, n.7, 1998; bem como do texto de José Carlos Braga, "Financeirização global: o novo padrão sistêmico de riqueza do capitalismo contemporâneo". In: José Luis Fiori, Poder e dinheiro. Petrópolis: Vozes, 1997.

2 Bacharel em Ciências Sociais pelo IFCH/Unicamp; Mestre em Ciência Política pelo IFCH/Unicamp; Doutora em História Econômica no IE/Unicamp. Autora do livro Estado e dependência no Brasil. São Paulo, Annablume, 2001. Professora de Ciência Política na Facamp (Faculdades de Campinas). E-mail: angelitams@uol.com.br. 3 José Carlos Braga, "Financeirização global: o novo padrão sistêmico de riqueza do capitalismo contemporâneo". In: José Luis Fiori, Poder e dinheiro. Petrópolis: Vozes, 1997.

30 Financeirização global e Estados Nacionais 
4) a "securitização" das finanças interconectando os mercados de créditos e de capitais, com a participação crescente das famílias por meio dos fundos de pensão, fundos mútuos e seguradoras; 5) o declínio da moeda e dos depósitos bancários enquanto substrato das operações de financiamento, substituídos pelos ativos financeiros que geram juros e decorrente perda do monopólio do crédito e do sistema de pagamento pelos bancos; 6) "endogeneização" dos déficits públicos, acompanhada de uma maior dependência dos governos em relação aos mercados financeiros internacionais; 7) criação de um sistema de moedas misto ("plurimonetário") gerando uma maior vulnerabilidade dos bancos centrais face às operações de mercado; 8) variabilidade interdependente das taxas de juros e de câmbio, sob a égide da moeda americana; 9) formação dos grandes "conglomerados de serviços financeiros"; 10) acirrada concorrência financeira - que se intensifica à medida que avançam as desregulamentações nos mercados nacionais - e que não é mais apenas competição entre bancos, ou entre estes e as demais instituições, ou intercorporações produtivas, mas a competição de todos contra todos. ${ }^{4}$

No centro deste "novo padrão sistêmico de riqueza" está o capital a juros - estamos assistindo à "institucionalização do rentismo", diz Braga5 . É sistêmico porque intrínseco ao sistema capitalista tal como ele está atualmente configurado, sendo parte constitutiva e fundamental da dinâmica do seu funcionamento. Não se trata de um novo "ciclo especulativo", a

(...) financeirização não decorre apenas da práxis de segmentos e setores - o capital bancário, os rentistas tradicionais - mas, ao contrário, tem marcado as estratégias de todos os agentes privados relevantes, condicionando a operação das finanças e dispêndios públicos, modificando a dinâmica macroeconômica ${ }^{6}$.

Por sua vez, as novas formas de internacionalização do capital, sob a financeirização global, têm suscitado o debate sobre o futuro dos Estados nacionais. Estes estariam com os dias contados, seja em proveito de um Estado "mundial" em gestação, seja porque o poder político dos Estados nacionais seria suplantado, num mundo "sem fronteiras", pelo poder do capital financeiro internacional.

$-\cdots-\cdots$

4 Braga, op. cit., p. 230

5 Idem, ibidem.

6 Idem, ibidem, p. 196.

cadernos cemarx, $n^{0} 2-2005 \mid 31$ 
Acreditamos, porém, ser preciso situar o debate à problemática do Imperialismo. Desta perspectiva, os processos de internacionalização realizam-se sob a dominância do capital monopolista de um determinado país tornando, por conseguinte, difícil qualquer possibilidade de surgimento de um mundo organizado sob a batuta de um Estado mundial, pois neste predominariam os interesses deste capital dominante, o que acirraria brutalmente os conflitos entre capitais imperialistas de origens diversas. Portanto, a não ser que se aposte no fim da concorrência intercapitalista mundial (!), é difícil imaginar um Estado mundial, "acima" dos interesses dos diferentes blocos no poder e Estados nacionais. Além disso, a idéia de que o poder político dos Estados nacionais estaria sendo suplantado, num mundo "sem fronteiras", pelo poder do grande capital financeiro internacional, supõe uma separação entre "poder e dinheiro" que, efetivamente, jamais existiu. E a maior interpenetração dos domínios do econômico e político, longe de implicar no enfraquecimento dos Estados Nacionais, fortalece aqueles Estados cujo capital que representa tem sólidas posições na economia mundial, aumentando a distância entre os países do Centro e os da Periferia, cujas relações continuam sendo, em grande parte, interestatais.

Ou seja, os Estados nacionais ocupam e continuarão a ocupar um papel crucial na defesa dos interesses dos seus capitalistas no cenário internacional. Prova disso é que os detentores da riqueza continuam concentrando esforços e dispensando enormes recursos às eleições de representantes tanto no Executivo como no Legislativo (Por que o fariam se o Estado não tivesse mais força diante do poder econômico?). E em busca da realização dos seus interesses, poderão sempre recorrer, além de ao seu próprio Estado de origem, a outros Estados, centrais ou periféricos. É neste terreno que identificamos aspectos políticos que, embora não sejam em absoluto novos, têm se intensificado nas últimas décadas. Estamos nos referindo ao caráter cada vez mais "supranacional" dos interesses capitalistas dominantes que compõem os blocos no poder nacionais também nos países centrais (também nos países centrais, pois no caso dos países periféricos e dependentes trata-se de um aspecto central e constante).

O que tem se traduzido na seguinte situação: os Estados nacionais precisam, cada vez mais, zelar pelos interesses não apenas de seus capitais domésticos, mas também dos interesses do capital imperialista dominante - norte-americano -, na medida em que se encontram todos articulados, em menor ou maior grau, à economia norte-americana ${ }^{7}$. A articulação de interesses intercapitalistas globais - funda-

\section{$-\cdots$}

7 Jessop, op. cit.

32 Financeirização global e Estados Nacionais 
mentalmente financeiros - no interior dos blocos no poder nacionais se, por um lado, reforça as relações hierárquicas entre os Estados nacionais na estrutura capitalista mundial, na medida em que os Estados nacionais dominantes atuam em bloco na defesa dos interesses do capital imperialista em geral; por outro lado, provoca uma maior heterogeneidade dos interesses que compõem os blocos no poder nacionais, tornando mais e mais complexas as relações Estado-classes sociais no interior de cada país, acirrando as contradições que perpassam o Estado. O que tem implicado em maiores limites à capacidade dos Estados nacionais do Centro em formularem sua política de compromisso:

(...) tornando mais difícil o desempenho da função estatal geral de manutenção da coesão social, [pois] politiza as suas funções econômicas de tal modo que o Estado não pode continuar a se apresentar eficazmente como um árbitro neutro colocado acima das classes sociais, e intensifica genéricas crisestendências no Estado capitalista que produzem uma crise permanente de instabilidade política e um declínio de legitimidade ${ }^{8}$.

Não obstante, menos que a uma condição de "ingovernabilidade" estatal intrínseca ao mundo atual, assistimos à novas configurações internas aos blocos no poder nacionais, modeladas pelo atual processo de internacionalização do capital. Dito de outra forma, se o Estado capitalista parece cada vez mais o "comitê executivo" da burguesia (financeira) internacional, que o árbitro neutro colocado acima das classes sociais, isto se deve menos ao declínio de poder dos Estados nacionais que às articulações do capital financeiro internacionalizado dentro de cada bloco no poder "nacional", de cada Estado, de cada formação social.

Neste sentido, os Estados capitalistas dominantes se parecem cada vez mais com os Estados periféricos e dependentes. O caráter "supranacional" dos interesses capitalistas que compõem os blocos no poder nacionais (e seus efeitos) é um aspecto distintivo dos Estados periféricos e dependentes (pelo menos deste que o capitalismo se transformou em imperialismo), por causa da situação de dependência em relação aos centros econômicos dominantes. Não obstante, a despeito de aproximações que possam ser feitas, diferenças cruciais sobrevivem. O Estado das nações dominan-

$--n_{--1}$

8 Jessop, op. cit., p. 22.

cadernos cemarx, $n ^ { 0 } - 2 - 2 0 0 5 \longdiv { 3 3 }$ 
tes, por mais que assuma a responsabilidade de defesa, externa e internamente, dos interesses não apenas dos seus próprios capitais, com base nacional, mas também de interesses dos capitais de origem estrangeira, ele continua desempenhando o papel, por excelência, de defesa de um posicionamento competitivo dos seus capitais no espaço econômico nacional e internacional, inclusive quando atrai investimentos estrangeiros diretos assegurando vantagens à penetração estrangeira; quer dizer, a defesa de interesses "forâneos" deve se articular ao objetivo maior de fortalecimento do capital local, de reprodução da sua posição dominante no cenário internacional. Coisa bem diferente se passa no caso dos Estados dos países periféricos e dependentes. Nestes casos, a globalização tem tido o efeito de reforçar a subordinação do Estado aos interesses do capital financeiro internacional.

A verdade é que o atual processo de internacionalização do capital, longe da homogeneização dos Estados Nacionais, tem reforçado, no plano político, a acalentada e constantemente lograda, "divisão de tarefas" no processo de acumulação capitalista mundial. Os Estados dominantes têm defendido com mais afinco o seu capital frente a outros competidores no mercado mundial, ao mesmo tempo em que os Estados periféricos e dependentes se esmeram em garantir a expansão dos interesses do capital estrangeiro no espaço econômico periférico. Ademais, a exportação-importação de capitais entre as potências capitalistas, em hipótese alguma se traduz em ingerência externa sobre a política do país importador, nos termos em que ocorre quando o país importador de capitais pertence à lista dos países pobres, periféricos e dependentes.

Enfim, o caráter cada vez mais supranacional dos interesses presentes nos blocos no poder nacionais produz efeitos radicalmente diferentes sobre os Estados nacionais, segundo a posição destes na cadeia imperialista. E além do fortalecimento das assimetrias de poder entre os Estados centrais e os periféricos, as transformações no interior dos Estados Nacionais têm reduzido a dimensão "pública" da esfera estatal também nos países centrais. A ideologia da separação entre o político e o econômico (entre poder e dinheiro) apresenta-se pelo avesso, mostrando sua verdadeira face no capitalismo atual. Portanto, encerraremos o desenvolvimento da abordagem dos temas acima "especulando" sobre possibilidades futuras: acreditamos que relações mais estreitas entre Estado e capital, sem dúvida, implicam, cada vez mais, numa crise de hegemonia que abre novas oportunidades para o avanço dos movimentos sociais identificados à luta pela transformação social.

34 Financeirização global e Estados Nacionais 